\title{
Correction to: Scintigraphic evaluation of remote perconditioning protection against unilateral renal ischemia/reperfusion injury in rats: a longitudinal study
}

\author{
Zahra Sedaghat $^{1} \cdot$ Hossein Fatemikia $^{1,2} \cdot$ Kaveh Tanha $^{3,5} \cdot$ Maria Zahiri $^{4} \cdot$ Majid Assadi $^{5}$
}

Published online: 10 October 2019

๑) Springer Nature B.V. 2019

\section{Correction to: International Urology and Nephrology https://doi.org/10.1007/s11255-019-02258-3}

The original article was published with incorrect article title. The correct title is "Scintigraphic evaluation of remote perconditioning protection against unilateral renal ischemia/ reperfusion injury in rats: a longitudinal study".

Publisher's Note Springer Nature remains neutral with regard to jurisdictional claims in published maps and institutional affiliations.

The original article can be found online at https://doi.org/10.1007/ s11255-019-02258-3.

Zahra Sedaghat

z.sedaghat@bpums.ac.ir

1 Physiology Department, School of Medicine, Bushehr University of Medical Sciences, Moallem Street, Bushehr 7514633341, Iran

2 Physiology Department, School of Medicine, Shiraz University of Medical Sciences, Shiraz, Iran

3 Medical Physics and Biomedical Engineering Department, Tehran University of Medical Sciences, Tehran, Iran

4 Department of Anatomical Sciences, School of Medicine, Bushehr University of Medical Sciences, Bushehr, Iran

5 The Persian Gulf Nuclear Medicine Research Center, Bushehr University of Medical Sciences, Bushehr, Iran 